\title{
Kelvin probe force microscopy for perovskite solar cells
}

\author{
Zhuo Kang ${ }^{1 \dagger}$, Haonan $\mathrm{Si}^{1{ }^{1 *}}$, Mingyue Shi ${ }^{1}$, Chenzhe $\mathrm{Xu}^{1}$, Wenqiang Fan ${ }^{1}$, Shuangfei $\mathrm{Ma}^{1}$, \\ Ammarah Kausar ${ }^{1}$, Qingliang Liao ${ }^{1}$, Zheng Zhang ${ }^{1}$ and Yue Zhang ${ }^{1,2^{*}}$
}

\begin{abstract}
Kelvin probe force microscopy (KPFM) could identify the local work function of surface at nanoscale with high-resolution on the basis of simultaneous visualization of surface topography, which provides a unique route to in-situ study of the surface information like the composition and electronic states. Currently, as a non-destructive detection protocol, KPFM demonstrates the unique potential to probe the basic nature of perovskite materials that is extremely sensitive to water, oxygen and electron beam irradiation. This paper systematically introduces the fundamentals and working mode of KPFM, and elaborates the promising applications in perovskite solar cells for energy band structures and carrier transport dynamics, trap states, crystal phases, as well as ion migration explorations. The comprehensive understanding of such potential detection engineering may provide novel and effective approaches for unraveling the unique properties of perovskite solar cells.
\end{abstract}

Keywords: Kelvin probe force microscopy, perovskite solar cells, carrier transport dynamics, trap states, ion migration

\section{INTRODUCTION}

Kelvin probe force microscopy (KPFM) also known as surface potential microscopy which detects the local surface potential with high resolution of nanometer scale offers extensive applications in the research of photovoltaic devices, semiconductors and metals structure [1-4]. Initially, Kelvin probe method, was first proposed by Lord Kelvin in 1898 [5], restricted to detect the contact potential difference (CPD) merely between connected metals. Afterward, a simple method was put forward by Zisman in 1932 [6] to acquire a high resolution of CPD up to $1 \mathrm{mV}$ by utilizing Kelvin probe which was limited to measuring the average surface potential of metal samples. Until 1991, with the advent of scanning probe microscopy (SPM), Nonnenmacher et al. [7] developed a new function in KPFM, which can measure the local electrostatic potential. Over the past 20 years, KPFM has gradually received attention and its applications range from metal/semiconductor structures to perovskite solar cells [8-14].

Perovskite solar cells are the third generation of new concept solar cells with high conversion efficiency, which is a new compound thin film solar cell developed in recent years and becomes a global research hotspot [15-18]. Even though the energy conversion efficiency of perovskite solar cells has increased rapidly and reached above $23 \%$ so far [19], the lack of comprehensive understanding of perovskite materials and the stability restrict their further development [20-26]. Especially, the potential difference due to the different energy band structures directly influences the spatial transportation of carriers, but the deep insights into the behavior of localized photogenerated charges are limited [27-30]. Moreover, the anomalous current-voltage hysteresis under different bias directions [31-35], trap statesinduced non-radiative recombination [34,36-39], phase segregation-induced degradation [40], and ion migration [41-45] also influence the development pace of perovskite solar cells towards commercial applications. Thus, it is of great significance to unveil the origin and nature of such phenomena and overcome the problems [46-49]. Several advanced characterization techniques demonstrate the competitive superiorities to trace, visualize and quantify the operational process [50]. Unfortunately, perovskite materials decompose facilely in water, oxygen, illumina-

\footnotetext{
${ }^{1}$ State Key Laboratory for Advanced Metals and Materials, School of Materials Science and Engineering, University of Science and Technology Beijing, Beijing 100083, China

${ }^{2}$ Beijing Municipal Key Laboratory of New Energy Materials and Technologies, University of Science and Technology Beijing, Beijing 100083, China

These authors contributed equally to this paper.

* Corresponding authors (emails: sihaonan@ustb.edu.cn (Si H); yuezhang@ustb.edu.cn (Zhang Y))
} 
tion and electron beam irradiation, which further increases the difficulty of characterizations [51-53]. KPFM could identify the local work function of the surface at nanoscale with high-resolution on the basis of simultaneous visualization of sample topography, which provides a unique route for in-situ studies of the composition, electronic states, energy band-bending, charge trapping, and surface reconstruction, which are related to the surface photovoltage and CPD [54-56]. Notably, compared with other characterization techniques, KPFM does not require complicated sample preparation and is implemented in a non-contact mode, to immensely minimize the damage of the sample $[57,58]$. The unique advantage of KPFM for work function detection shows the promising potential to probe the basic nature of environment-sensitive materials and the operation mechanism of related devices [59-62].

In this review, we highlight the fundamental principle, working modes, instrumental parts and the development in KPFM and systematically summarize its application in perovskite solar cells. The relevant core-problems about the energy band structures and carrier transport dynamics, trap states, crystal phases as well as ion migration exploration have been elaborated in detail.

\section{FUNDAMENTALS OF KPFM}

On the basis of atomic force microscope (AFM), KPFM is developed with the combination of the macro-Kelvin probes [63]. The cantilever of the AFM is a force sensor with high sensitivity and its vibration depends on the tipsample interaction, which can measure the CPD even if the capacitance between the probe and sample is extremely tiny, while KPFM considers the tip-sample system as a capacitor [64].

The research shows that the surface work function depends on the energy distinction between the vacuum level and Fermi energy level $[58,65]$. When there is an electrical contact between two substances, the process that electrons flow from one side with a small work function to the other side with a large work function produces the opposite charges on the substances, leading to the formation of CPD and inducing an electric field [66]. As a result, the electrostatic force is generated between the tip and sample due to the difference between their Fermi levels. In a KPFM system, an alternative voltage $\left(V_{\mathrm{AC}}\right)$ and a direct voltage $\left(V_{\mathrm{DC}}\right)$ are introduced to the tip, where the $V_{\mathrm{AC}}$ produces electrostatic oscillations and the $V_{\mathrm{DC}}$ eliminates the electrostatic oscillations caused by potential difference between the tip and the sample [67]. A lock-in amplifier which is not sensitive to
$V_{\mathrm{DC}}$ is utilized to track the vibration of the cantilever and obtain the CPD through the extraction of the electrostatic force. By controlling $V_{\mathrm{DC}}$ equal to CPD through the feedback loop, the output signal of lock-in amplifier that is proportional to the difference between CPD and $V_{\mathrm{DC}}$ is eliminated, namely the cantilever vibration amplitude is eliminated. In this way, we can find that the electric field and charges are eliminated through the external bias $V_{\mathrm{DC}}$ to the system as a bulking voltage. Therefore, once we obtain the work function of a tip (marked as $\Phi_{\text {tip }}$ ), the work function of a sample (marked as $\Phi_{\text {sample }}$ ) can be acquired by a simple formula: $\Phi_{\text {sample }}=\Phi_{\text {tip }}-e \times C P D$, where $e$ is the electronic charge [68]. At the same time, we can obtain a defined formula of CPD between the conductive AFM tip and a sample surface by transforming the above formula to another form: $\mathrm{CPD}=\left(\Phi_{\text {tip }}-\Phi_{\text {sample }}\right) / e$.

Here, we use a visual diagram to understand CPD thoroughly. Fig. 1a-c show the energy level diagram of the tip and sample surface in three states [57]. First, as shown in Fig. 1a, at a certain distance of $d$, the sample and the tip present different Fermi level and have no electrical interaction. In Fig. 1b, the tip and the sample are close enough to keep electric contact. As previously described, the electrons will transfer from the sample to the tip resulting from their different work functions which will generate a CPD and finally their Fermi levels will keep constant in a line, reaching an equilibrium [69]. Fig. 1c shows the previous state as shown in Fig. 1a because when we add an external bias $V_{\mathrm{DC}}$ that is equal to the CPD between the tip and the sample, the surface charges are eliminated on the tip and the sample.

KPFM is an instrument based on the non-contact atomic force microscopy [66]. Hence, KPFM can detect the local surface potential by two working modes: amplitude modulation mode (AM) and frequency modulation mode (FM) [70]. The topography of the sample surface and CPD between the tip and the sample can be detected in both AM and FM mode, whereas their resolution is different due to different measuring mechanisms. AM-KPFM aims to eliminate the electric force which achieves a super high energy resolution while FM-KPFM with high spatial resolution $[68,71]$ aims to eliminate the electric force gradient. At present, it is still indispensable to enhance the resolution of KPFM in response to its wide application.

As above, we make a comparison of the AM and FM mode in some respects. Primarily, they have similarity in external bias: an AC bias $V_{\mathrm{AC}}$ at frequency $\omega_{\mathrm{AC}}$ plus a DC bias $\mathrm{V}_{\mathrm{DC}}$ are applied between the tip and sample. In the AM-KPFM, meanwhile an electric force consisting of 


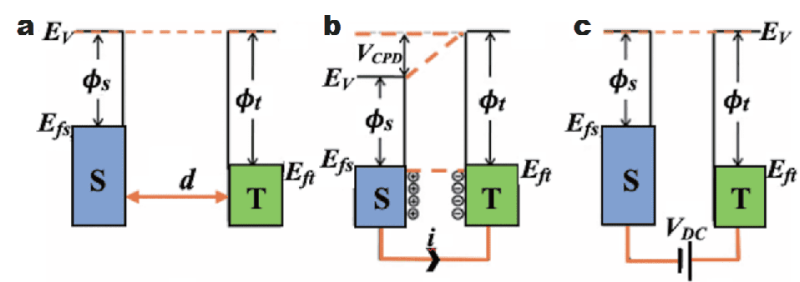

d

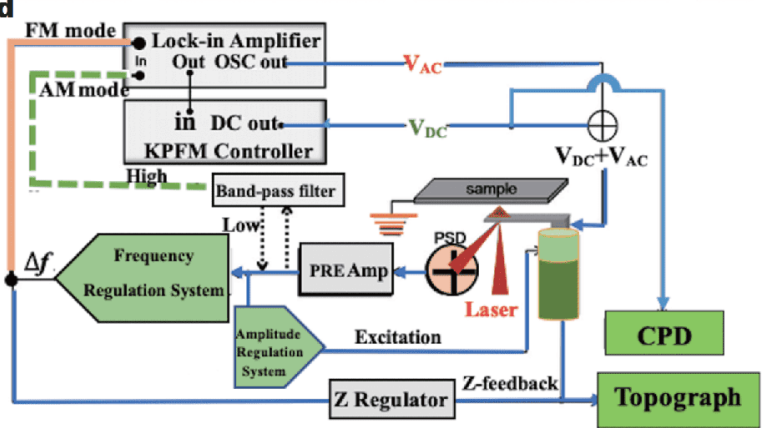

Figure $1(a-c)$ Three conditions of energy levels of the sample (S) and the tip (T): (a) The tip and sample surface have no contact. (b) The tip and sample have contact and their Fermi levels keep constant. (c) Applying an external bias $\left(V_{\mathrm{DC}}\right)$ with adverse direction between the tip and sample. $E_{\mathrm{V}}$ is the vacuum energy level. (d) The setup schematic diagram of both AM-KPFM and FM-KPFM. The bold line indicates the FMmode and the dashed line indicates the AM-mode [70]. Copyright 2010, Elsevier B.V.

three compositions $\left(F_{\mathrm{DC}}, F_{\omega}, F_{2 \omega}\right)$ is generated, where $F_{\omega}$ and $F_{2 \omega}$ are single and double frequency AC electrostatic force, respectively. If we regulate $V_{\mathrm{DC}}$ to equal to the $\mathrm{CPD}$, $F_{\omega}$ would reduce to zero, inducing a null value to the amplitude of cantilever. Besides that, AM-KPFM can still be further divided into other two modes: a dual pass process and dual frequency mode. The former fits small transformation in potential while the latter fits large potential transformation. An electric force gradient consisting of three elements $\left(\partial F_{\mathrm{DC}} / \partial z, \partial F_{\omega} / \partial z, \partial F_{2 \omega} / \partial z\right)$ is generated in the FM-KPFM. It is prevalent to utilize the resonance frequency $\left(\omega_{0}\right)$ shift of cantilever to detect electric force gradient. Regulating $V_{\mathrm{DC}}$ to eliminate the two side peaks of $\omega_{0}$ cancels the electric force gradient $[66,71]$.

Finally, we illustrate several significant schematic setup and components of KPFM [71]. Fig. 1d contains lock-in amplifier, frequency and amplitude regulation system. The vibration state of the probe detected by a beam deflection is transformed to a signal exported from the position sensitive photodiode (PSD), which later goes into frequency and amplitude regulation system to be detected. Therefore, lock-in amplifier is an essential composition which is sensitive to detect phase. According to the setting principle of lock-in amplifier, we could consider it as a blender where two signals blend together. The export of the blender may be a DC voltage or others which hinge on the frequency of two signals. The lock-in amplifier with AM mode is applied to read high frequency signals from a band-pass filter after an output from PSD that is shown by dash line indicated in Fig. 1d. In the FM mode, the lock-in amplifier directly reads the signal from frequency regulation system and detects the frequency deviation caused by electrostatic force [64]. In addition, here the lock-in amplifier regulates the DC bias by inputting the signal to the KPFM controller. Eventually, the topography and CPD are received through the above measurement set-up apparatus $[69,72]$.

\section{APPLICATION OF KPFM}

\section{Energy band and carrier transport dynamics analysis}

The charge generation and extraction within the perovskite are the key to the overall device performance. The energy band matching of different layers is of vital importance for the efficient charge transfer [73-77]. The ultraviolet photoemission spectroscopy (UPS) has been widely used to explore the position of energy levels [78]. But there are many requirements for testing samples, such as high conductivity and suitable size [79]. Different from UPS, KPFM could detect the work function of various materials under lighting and heating conditions [63]. Through the potential offset between the probe tip and the material surface, the CPD which is equal to the difference of work function of the AFM probe tip and the sample can be acquired in nanoscale. Hence, the Fermi level of the detected material could be acquired easily. Currently, KPFM has been widely used to acquire the energy band structures. Especially, the energy band structure of the $\mathrm{SnO}_{2}$-based electron transport layer is detected by KPFM [80]. The mapping of the work function demonstrates that the Fermi level of $\mathrm{SnO}_{2}$ with ethylene diamine tetraacetic acid is closer to the conduction band of perovskite than that of the pure $\mathrm{SnO}_{2}$. KPFM is also applied to identify the energy band position of perovskite with $\mathrm{Cu}^{+}$doping [81]. The change of Fermi level proves that the addition of $\mathrm{Cu}^{+}$is a promising strategy to modulate the band structure for matching energy bands. For all-inorganic $\mathrm{CsPbBr}_{3}$ perovskite quantum dots sensitized solar cells, the anomalous potential distribution in different layers of solar cells under different illumination is obtained by KPFM [82].

The accumulation of carriers induces an un-negligible effect on the potential, which has been investigated by 
KPFM. In Fig. 2 of the cross-sectional potential distribution, there is a uniform electric field in the perovskite solar cells in the dark. However, when the devices are exposed to white light, the separation and transmission of photogenerated electrons and holes increases, while the CPD of the hole transport layer and the electron transport layer decreases. Meanwhile, the accumulation of holes at the hole transport layer and perovskite interface also indicates that the extraction efficiency of holes in the device is lower than that of
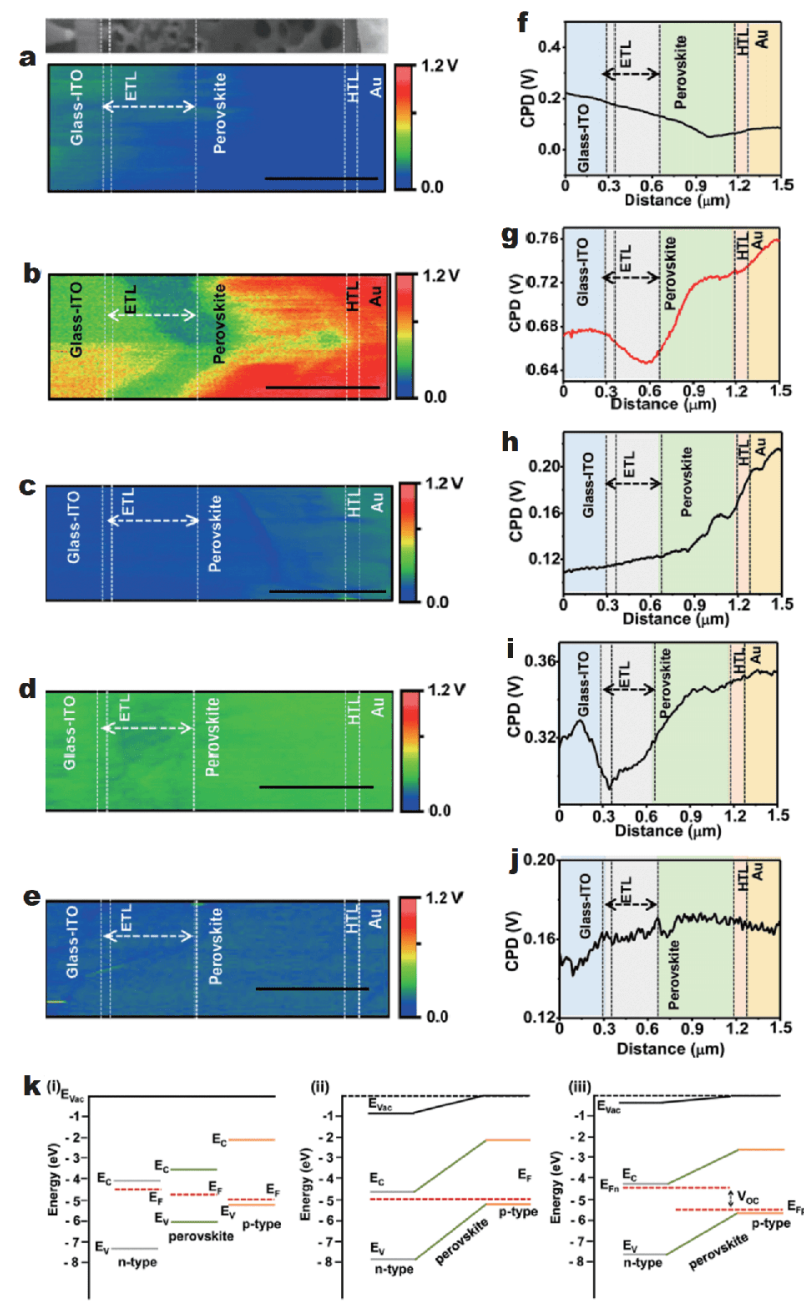

Figure 2 (a-e) Surface potential images across the cross section of the solar cell under dark condition, solar illumination, shorter (UV), medium (green), and longer (red) wavelength of light, respectively. ( $\mathrm{f}-\mathrm{j}$ ) Potential depth profiles across the layers of the solar cell under dark condition, solar illumination, UV, green, and red light illuminations, respectively. (k) (i) Vacuum level alignment along n-type/perovskite/ptype material in solar cell before contact. (ii) Fermi level alignment after contact in the dark (equilibrium condition). (iii) Separated quasi-Fermi levels for electrons and holes under illumination [80]. Copyright 2017, American Chemical Society. electrons in electron transport layer. Hence, the potential distribution in perovskite solar cells is significantly affected by carrier accumulation, which is corresponding to the work functions between different layers. In addition, the distribution of charge under different wavelength (ultraviolet, green and red) illumination is also investigated. Thus, both $\mathrm{TiO}_{2}$ and perovskite can be excited by ultraviolet light. Because the conduction band of electron transport layer is occupied by the self-excited electrons, it is difficult for the perovskite's electron to jump in electron transport layer, while the excess electrons lead to the CPD reduction of electron transport layer. Under the green light, the distribution of CPD is similar to that under white light, while the perovskite cannot excite charge carriers under monochromatic light as much as that under white light, which leads to a poor surface potential difference. As the red light is not enough to excite perovskite, the surface potential does not change significantly when there is barely no carrier generation or accumulation in the perovskite solar cells.

KPFM is also utilized to identify the charge separation location in perovskite solar cells with typical mesoporous and planar structures by tracing the potential fluctuation [83]. The major potential drop exists at the perovskite/ mesoporous $\mathrm{TiO}_{2}$ interface for the mesoporous structured perovskite solar cell. While potential fluctuation for planar perovskite solar cells is at both sides of the perovskite layer. The position of the potential drop can be changed from the perovskite/ $\mathrm{TiO}_{2}$ interface to perovskite/ hole transport layer interface by incorporating excess $\mathrm{PbI}_{2}$. It indicates that the distribution of the electrical potential in the planar perovskite solar cells is sensitive to the composition of the perovskite, which can be easily tuned by changing the component of the perovskite. KPFM provides the charge separation and transmission images by detecting the surface work function. Both the energy band structure and carrier transport dynamics have been investigated by KPFM, which promotes the development of perovskite solar cells $[84,85]$.

\section{Trap states investigation}

Energy levels of impurity atoms are inevitably introduced into the band gap during fabricating perovskite process. If trap states are located on the surface of the material, some additional energy levels become surface states. Meanwhile, crystal defects and impurities in the grain boundaries result in the formation of trap states level which may act as non-radiative recombination sites in the band gap. To investigate trap states in perovskite materials, KPFM is a powerful protocol for not only 

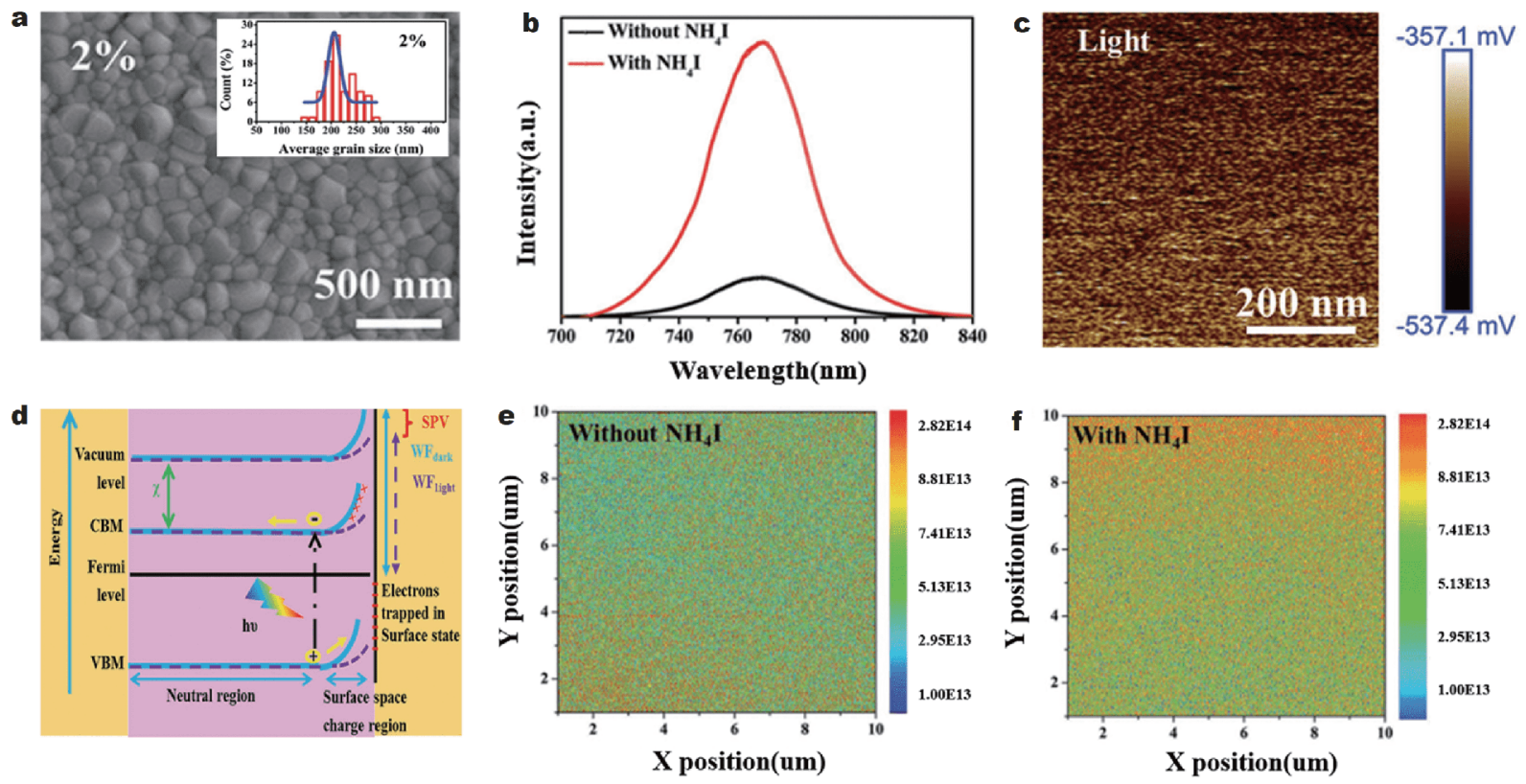

Figure 3 (a) Top view SEM images of perovskite with $\mathrm{NH}_{4} \mathrm{I}$, (b) photoluminescence spectroscopy of perovskite without and with $\mathrm{NH}_{4} \mathrm{I}$ additive, (c) surface potential mapping of perovskite film with $\mathrm{NH}_{4} \mathrm{I}$, (d) schematic energy band diagram for the generation of surface photo-voltage, (e, f) carrier concentration distribution images of perovskite film without and with $\mathrm{NH}_{4} \mathrm{I}$ [91]. Copyright 2017, WILEY-VCH.

unveiling energy band bending induced by defects but also gaining surface potential under different illumination conditions by means of measured surface work function $[70,86,87]$. The photoluminescence (PL) spectrum has been proposed to analyze the crystal quality and recombination process. But the spatially resolved imaging cannot be acquired by the above methods [88]. Although the fluorescence microscopy could obtain the spatially resolved PL information, the perovskite materials tend to degradation. Compared with electrochemical and optical measurements, KPFM is a non-destructive and noncontact method which can avoid the bulk recombination under any reasonable ambient conditions [89-92].

The surface defects of perovskite films can be studied in the dark or under illumination, by applying KPFM measurements [93]. Especially, when the trap states are spatially located at the surface, the electrons or holes are accumulated, which leads to the formation of a local space charge region-induced energy band bending in Fig. 3d [94]. The type of surface states determines the direction of the band bending. If the terminal surface states are acceptor-type causing the accumulation of electrons, there are upward band bending and electron depletion region, indicating that the surface states in perovskite materials are belonging to this type, and if the surface states are donor-type accumulating holes, down- ward band bending and hole depletion region exists there. More surface trap states contribute to greater depletion layer region and then result in a large magnitude of the band bending. Under illumination, excess photo-generated carriers come into being and the diffusion current causes the redistribution of space charges [95]. Meanwhile, photo-generated holes could screen electrons accumulated at the surface, which reduces the built-in voltage and the degree of band bending.

The difference of surface potential of perovskite materials measured by KPFM with different light intensity is defined as surface photo-voltage (SPV), which is same as the difference of surface work function, manifesting the degree of change in band bending. The SPV is generated by the transfer and separation process of charge carriers, leading to the redistribution of surface charges under illumination [91]. Therefore, the value of SPV is related to surface states population which causes band bending. Therefore, SPV is employed to represent the density of surface states and higher SPV value means more trap states at the surface.

Controlling perovskite crystal growth and reducing defect density are two key factors for achieving solar cells with excellent performance. A $\mathrm{NH}_{4} \mathrm{I}$ additive assisted method which simultaneously improves nucleation and crystal growth is utilized for high quality perovskite films. 
In Fig. 3a, b, large grains are obvious with a high steadystate PL intensity, upon the addition of $\mathrm{NH}_{4} \mathrm{I}$. To investigate the surface properties of perovskite films with or without $\mathrm{NH}_{4} \mathrm{I}, \mathrm{KPFM}$ is applied under dark and illumination for getting surface potential and surface photo-voltage. SPVs decrease from 75 to $27 \mathrm{mV}$ for pristine to the one with $\mathrm{NH}_{4} \mathrm{I}$, respectively (Fig. 3c) which suggests that $\mathrm{NH}_{4} \mathrm{I}$ effectively reduces electronic trap states density near the surface of perovskite films, supressing the recombination between the trapped electrons and free holes. Moreover, carrier concentration at the surface can also be calculated by surface potential attained from KPFM. Especially, Kelvin probe collects the two-dimensional imaging of the CPD between conductive tip and sample, and the value of $\mathrm{CPD}$ is $V_{\mathrm{CPD}}=-\left(\Phi_{\text {tip }}\right.$ $\left.-\Phi_{\text {sample }}\right) / e=-\left(\Phi_{\text {tip }}-\chi+\left(E_{\mathrm{F}}-E_{\mathrm{C}}\right)\right) / e$, where $\Phi_{\text {tip }}$ is the work function of the conductive tip, $\Phi_{\text {sample }}$ is the work functions of the sample, $\chi$ is the electron affinity of the sample, and $E_{\mathrm{F}}, E_{\mathrm{C}}$ are the Fermi energy level and conduction band energy, respectively. According to Boltzmann approximation, the concentration of electrons in n-type semiconductors is $n=N_{\mathrm{C}} \exp \left(\left(E_{\mathrm{F}}-E_{\mathrm{C}}\right) /\left(k_{\mathrm{B}} T\right)\right)=N_{\mathrm{C}}$ $\exp \left(\left(q V_{\mathrm{CPD}}-\Phi_{\text {tip }}+\chi\right) /\left(k_{\mathrm{B}} T\right)\right)$, where $n$ is the concentration of electrons, $N_{\mathrm{C}}$ is the effective density of states in the conduction band, $k_{\mathrm{B}}$ is the Boltzmann constant and $T$ is the temperature [96]. Through highly-sensitive KPFM, the carrier concentration mappings of perovskite with and without $\mathrm{NH}_{4} \mathrm{I}$ are shown in Fig. $3 e, f$. The $V_{\text {CPD }}$ of $\mathrm{NH}_{4} \mathrm{I}$ reduces from -355 to $-423 \mathrm{mV}$ and the carrier concentration at the surface improves from $6.73 \times 10^{13}$ to $9.67 \times 10^{14} \mathrm{~cm}^{-3}$. Therefore, with $\mathrm{NH}_{4} \mathrm{I}$, low surface trap states density and high carrier concentration are simultaneously demonstrated by KPFM measurements.

Band bending discrepancy near the surface of the perovskite film and the difference electronic trap states caused by hypophosphorous acid are analyzed through investigating surface work function of perovskite films under different light intensity via KPFM [93]. Besides, the difference of the surface work function in the dark and under illumination is also adopted to demonstrate that perovskite films with chlorobenzene treatment show low trap states and well photo-electronic properties [95]. Obviously, KPFM is considered as a promising protocol to study surface trap states in perovskite materials.

KPFM method is used to investigate the degradation process of perovskite materials by mapping the CPD and surface potential difference between grain boundaries and grains of perovskite films [97]. When perovskite films are exposed to high humidity environment, the CPD at grain boundaries becomes lower than the fresh films, which implies that non-perovskite phase originates from grain boundaries towards grain interiors. By the bias voltage dependent measurements, the CPD between grain boundaries and grains of degraded sample takes more time to return previous value than that of fresh films. It suggests that more ionic defects exist at grain boundaries after perovskite films become decomposed. Based on the detection of the local property of the trap states in fresh films and degraded films, a post thermal treatment method (PTT) is adopted to remove chemical residues such as $\mathrm{CH}\left(\mathrm{NH}_{2}\right)_{2} \mathrm{I}$, oxygen and water vapor. As a result, a more possible $\mathrm{PbI}_{2}$-terminated perovskite surface with lower ionic defects shows the lower CPD between grain interiors and grain boundaries. PTT-processed perovskite films with few ionic defects is beneficial to achieve high stability and efficiency of the devices.

Obviously, the SPV at the grain boundaries are enhanced with the light intensity, which indicates that the grain boundaries play an important role in separating the photo-generated carriers [98]. In terms of CPD mapping through KPFM, the prolonged thermal annealing is effective in reducing average surface potential, which contributes to the new formed $\mathrm{PbI}_{2}$ phase [97]. Thus, the researchers confirmed that $\mathrm{PbI}_{2}$ greatly reduced the surface recombination in the perovskite films and controlled the carrier behavior along the heterojunctions due to electronic bands at the grain boundary from downward bending to upward bending by passivating surface trap states. Furthermore, the surface potential distribution between grain boundaries and grains in mixed perovskites is more uniform than that of threedimensional perovskite materials [99]. Benzoquinone and hydroquinone additives also play a similar role in achieving a flat surface potential distribution between grain interiors and grain boundaries [100]. It is indicated that the band bending at grain boundaries reduces and the electron states are trapped by the decrease of surface defects, which is in favor of the efficient charger-carrier separation and high performance. Therefore, KPFM is considered as an effective method to get a comprehensive and in-depth understanding of the trap states in perovskite materials.

\section{Phase identification}

In the field of material science, it is essential to accurately identify the composition at different localized regions for the further analysis. However, researchers often cannot recognize different specific phases only through conventional characterizations like optical microscopy and scanning electron microscopy (SEM). For instance, the 
a
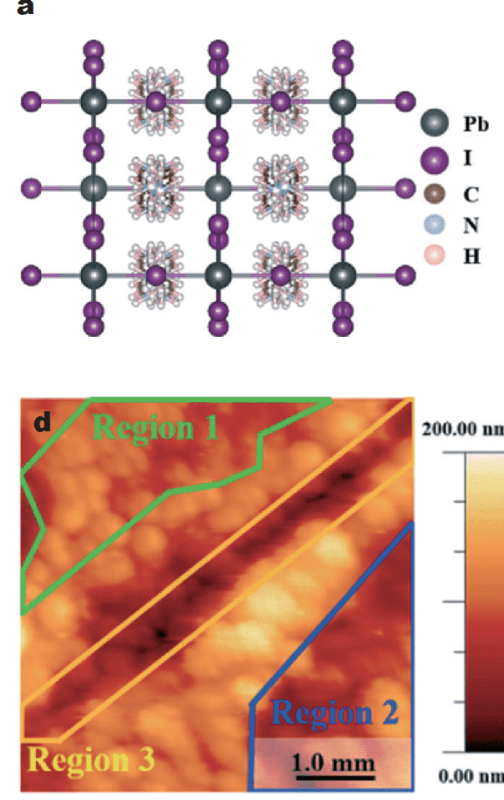

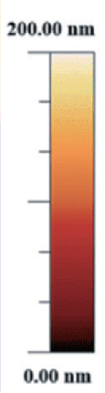

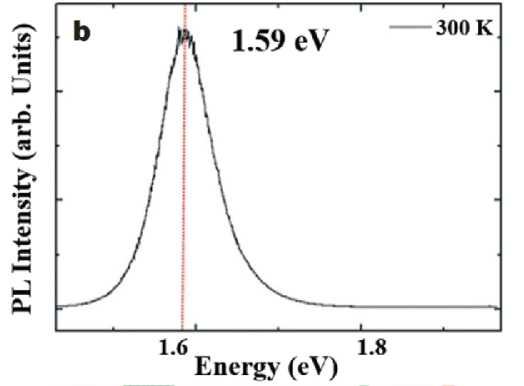

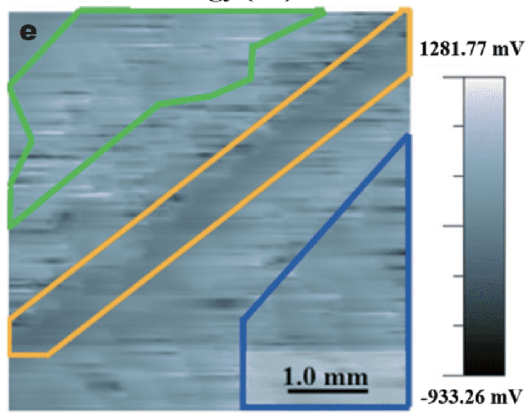

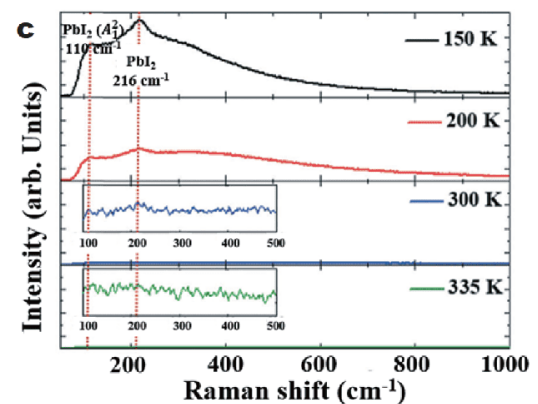

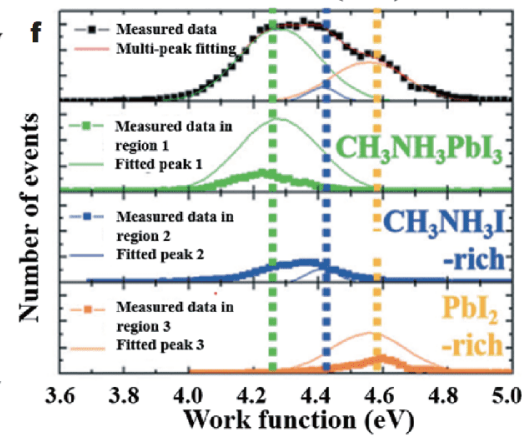

Figure 4 (a) Atomic crystal structure of perovskite by VESTA, (b) PL spectra of perovskite films under ambient conditions, (c) Raman spectra of perovskite crystal, (d) topography image of different regions, (e) surface potential mapping of different regions, (f) work function deconvolution for $\mathrm{CH}_{3} \mathrm{NH}_{3} \mathrm{PbI}_{3}, \mathrm{PbI}_{2}$, and $\mathrm{CH}_{3} \mathrm{NH}_{3} \mathrm{I}$ phases, respectively [102]. Copyright 2017, the Royal Society of Chemistry.

electron backscatter diffraction technique could obtain the microstructures and confirm the crystalline phases. But the beam-sensitive perovskites cannot withstand long-term exposure processing [101]. Although the crystalline phases can be confirmed by X-ray diffraction, the spatially resolved imaging cannot be acquired by such techniques [63]. Due to the difference between the Fermi level and the vacuum level for each phase, there are different work functions presented in different phases. By making use of divergence of work function, KPFM gives direct information on different phase identification through surface potential mapping [102-105].

For crystal and optical properties, the crystal structure and temperature dependent Raman spectra of perovskite $\left(\mathrm{CH}_{3} \mathrm{NH}_{3} \mathrm{PbI}_{3}\right)$ are performed (Fig. 4a-c). It is important that the atomic crystal structure is in agreement with HRTEM images and, according to the optical tests, there is degraded lead iodide on the surface due to Raman peaks around $200 \mathrm{~cm}^{-1}$ under $150 \mathrm{~K}$. As shown in Fig. $4 \mathrm{~d}-\mathrm{f}$, the work function deconvolution is also derived from surface potential mapping through KPFM measurements for the further study of the specific electronic properties and spatial distribution in perovskite materials with some external conditions that may cause perovskite decomposition [106]. Compared with some earlier results about perovskite work function, it can be considered that the low work function of $\mathrm{CH}_{3} \mathrm{NH}_{3} \mathrm{PbI}_{3}$ with $4.00 \mathrm{eV}$ work function (region 1) is due to the degradation. Meanwhile, the other two regions can be attributed to lead iodide phase and $\mathrm{CH}_{3} \mathrm{NH}_{3} \mathrm{I}$ phase, which are both the products of $\mathrm{CH}_{3} \mathrm{NH}_{3} \mathrm{PbI}_{3}$ decomposition. Thus, KPFM test is employed to study the surface electronic structure of perovskite materials and the deconvolution of work function, which shows an n-type characteristic on the surface. Also, three regions with different components which include the perovskite and its degradation products are distinguished accurately. Additionally, the surface potential mapping of $\mathrm{CH}_{3} \mathrm{NH}_{3} \mathrm{PbBr}_{3}$ and work function with the deconvolution by KPFM are also used to decipher electronic structure and phases [107]. Similar to $\mathrm{CH}_{3} \mathrm{NH}_{3} \mathrm{PbI}_{3}$, the reduced perovskite work function implies a possible change in the spatial distribution of $\mathrm{CH}_{3} \mathrm{NH}_{3} \mathrm{Br}$ phase and $\mathrm{PbBr}_{2}$ phase, which is consistent with the deconvolution calculation of work function. Therefore, the intrinsic electronic properties (p-type) and band structures of $\mathrm{CH}_{3} \mathrm{NH}_{3} \mathrm{PbBr}_{3}$ are established by KPFM. In general, it is beneficial to further study the characteristics by the accurate phase identification of different regions in perovskite materials.

KPFM is also applied in conjunction with optical 
microscopy and SEM to clearly determine the location of the phases. The distribution of lead iodide at nanoscale and its effect on the defect passivation in $\left(\mathrm{CH}\left(\mathrm{NH}_{2}\right)_{2} \mathrm{PbI}_{3}\right)_{0.85}\left(\mathrm{CH}_{3} \mathrm{NH}_{3} \mathrm{PbBr}_{3}\right)_{0.15}$ perovskite films are investigated through the combination of SEM, KPFM and fluorescence lifetime imaging microscopy (FLIM) [108]. Firstly, it is obvious that there are some grains with different contrast according to SEM images. Secondly, from surface potential mapping, the CPD of those different grains is smaller than that of other grains, even grain boundaries, which reveals the discrepancy of work function between grains with the different contrast. To get further insight into the defect passivation of the influence of those different grains, FLIM is used to provide insight carrier dynamics in the different regions. It can be concluded that those grains with lower CPD are lead iodide phase, and the carrier lifetime of the region with more lead iodide phase is longer than that of the phase with less lead iodide. So the above results show clear spatial distribution of lead iodide and the passivated defect states which facilitate the prolonging carrier lifetime of perovskite films. Besides, KPFM is performed for the direct observation of perovskite $\left(\mathrm{CH}_{3} \mathrm{NH}_{3} \mathrm{PbI}_{3}\right) / \mathrm{WS}_{2}$ heterostructures and the accurate identification of the location of the $\mathrm{WS}_{2}$ phase and perovskite phase [109]. Although it is difficult to distinguish the difference between the two phases by optical microscopy and AFM topography, there is a clear boundary between the two phases via surface potential mapping. It is obvious that the regular regions with deeper colors can be attributed to $\mathrm{WS}_{2}$ phase. As mentioned above, by combining perovskite topography images with surface potential mapping, KPFM measurements is a convenient and powerful technique which could be widely used for accurate phases or components identification on the basis of different work function.

\section{Ion migration investigation}

Ion migration in organic-inorganic perovskite materials is a key issue to $J-V$ hysteresis in difference under different scan rates and scan directions [110-114]. Determining the fundamental mechanisms of ion migration and main factors is essential for understanding the intrinsic working principle of perovskite solar cells. Therefore, the reasonable regulation of ion migration is conducive for fabricating perovskite solar cells with a high stability, high performance and low hysteresis, and thus further promoting optimistic development of perovskite photoelectric devices. On one hand, KPFM is capable of detecting local potential changes caused by the ion migration at precise nanoscale, giving the information on physical properties and photo-induced carriers. On the other hand, it is imperative to deeply investigate ion migration which is related to device stability and currentvoltage hysteresis by detecting the CPD distribution [115-117]. For instance, bias dependent KPFM was used to confirm Fermi energy level shift and hysteresis induced by ion migration in perovskite films [118].

To accurately elaborate the key role of grain boundaries in mixed perovskite materials $\left(\left(\mathrm{CH}\left(\mathrm{NH}_{2}\right)_{2} \mathrm{PbI}_{3}\right)_{0.85}\left(\mathrm{CH}_{3} \mathrm{NH}_{3} \mathrm{PbBr}_{3}\right)_{0.15}\right)$, KPFM was used to detect the local surface potential redistribution caused by ion migration, which affects the performance of perovskite solar cells [119]. There is different CPD in the same region under different bias voltage (Fig. 5a). As presented in Fig. 5d, e, it is obvious that the change of CPD caused by negative bias is greater than that caused by positive bias. It could be considered that the $720 \mathrm{~s}$ of recovery time after the bias voltage removed is related to the ion migration. Moreover, as shown in Fig. 5b, c, compared with grain interiors, the change of CPD at grain boundaries is severe under large bias, which indicates that grain boundaries are the main channels for the ion migration. To further get insight of the effect of grain boundaries on ion migration, the CPD mapping images under different illumination are detected by KPFM. As depicted in Fig. 5f, built-in potential generated by work function difference between $\mathrm{TiO}_{2}$ and perovskite could separate photo-generated hole-electron pairs under illumination. Meanwhile, bight and obvious outline in the CPD mapping is in good agreement with the previous result that is grain boundaries playing a critical role in ion migration. As a result of ion migration, $\mathrm{MA}$ and $\mathrm{Pb}$ vacancy appears in the valence band (p-type) and the I vacancies appear in the conduction band (n-type) representing that there is band bending near the grain boundary. Similarly, KPFM under $0-3.5 \mathrm{~V}$ bias voltage is to gain the CPD mapping in-turn to study the amount of extra $\mathrm{PbI}_{2}$ affecting ion migration at grain boundaries [113]. Through getting insight of internal mechanism of operation process, low-hysteresis and high-performance devices are achieved by incorporating proper $\mathrm{PbI}_{2}$. Moreover, KPFM is also used to investigate the photoinduced bulk polarization [120,121]. Under illumination, the photoexcited charges exacerbate the rotation of $\mathrm{CH}_{3} \mathrm{NH}_{3}^{+}$, consequently enhancing the dipolar polarization. For perovskite materials, polarizationinduced fields contribute to internal field, which effectively enhances the charge separation and restrains charge recombination [122]. To clarify the role of 

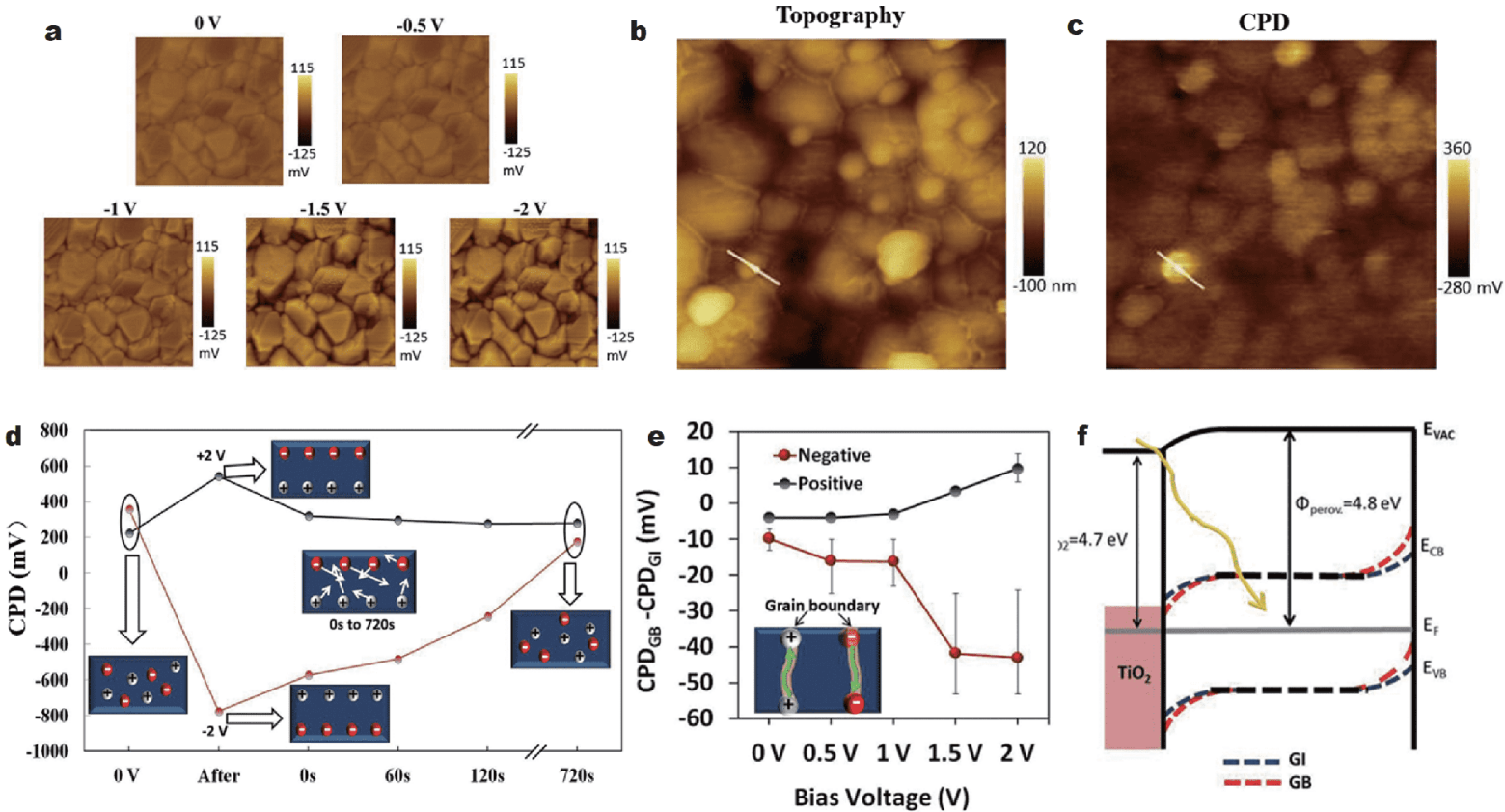

Figure 5 (a) Average CPD images under different bias, (b, c) topography and CPD mapping under $-7 \mathrm{~V}$ bias voltage, (d) average CPD as a function of time after the bias voltages, (e) plot of the differences between contact potential differences within the grain interior and at the grain boundary under negative and positive bias voltage, (f) energy band diagram of perovskite and perovskite/ $\mathrm{TiO}_{2}$ interface [115]. Copyright 2016, WILEY-VCH Verlag GmbH \& Co. KGaA, Weinheim.

chlorine on bulk polarization, KPFM has been proposed to visualize the local surface potential change of grain boundaries and bulk in perovskite films. The incorporation of chlorine results in well-defined CPD mapping at grain boundaries and bulk, which indicates the decreased surface charged defects. While the ionic and charged defects could screen the photoinduced bulk polarization. Thus, the chlorine addition effectively enhances the photoinduced bulk polarization and further improves the performance of perovskite solar cells [123].

In addition to ion migration at grain boundaries, the ion migration at the interface of perovskite solar cells was also studied by KPFM [124,125]. According to CPD mapping of the interfaces of the perovskite layers, the $J-V$ hysteresis resulted from the accumulated charges at the interface induced by ion migration [126]. The crosssectional image of perovskite solar cell in Fig. 6a shows that $\mathrm{Li}$ ions are doped in the hole transport materials to investigate how the extrinsic ions affect the performance of perovskite solar cells [127]. The cross-sectional potentials of perovskite solar cells display obvious boundaries between the different regions, as shown in Fig. 6 b, c. Under dark conditions, the positive and the negative pre-bias lead to the potential change, especially at the perovskite/ $/ \mathrm{TiO}_{2}$ interface. Fig. $6 \mathrm{~d}$ shows the corresponding cross-sectional potential images of perovskite solar cells, which indicates the obvious potential drop at the interface. Generally speaking, high potential change is related to the efficient charge-carrier separation, in agreement with the theory that $\mathrm{Li}$ ions aggregated in the interface contribute to the charge separation. From current-voltage curves of perovskite solar cells with Lifree HTL and Li-doped HTL as illustrated in Fig. 6e, f, it is obvious that there is more hysteresis in perovskite solar cells with Li-doped HTL. Moreover, the influence of the ion migration in moisture on perovskite films was studied by KPFM [35]. It can be observed that small CPD difference between grain boundaries and interiors under controlled moisture conditions indicates the moistureinduced $\mathrm{PbI}_{2}$ passivates the grain boundaries and suppresses the ion migration. As a result, the energy band bending and possible passivation of ion migration at grain boundaries eventually improve the device performance. Thus, getting a deep understanding and making a precise control of ion migration in perovskite grain boundaries and interfaces based on KPFM could suppress the hysteresis in perovskite solar cells. Surface potential measurements by KPFM, enable to gain a comprehensive 

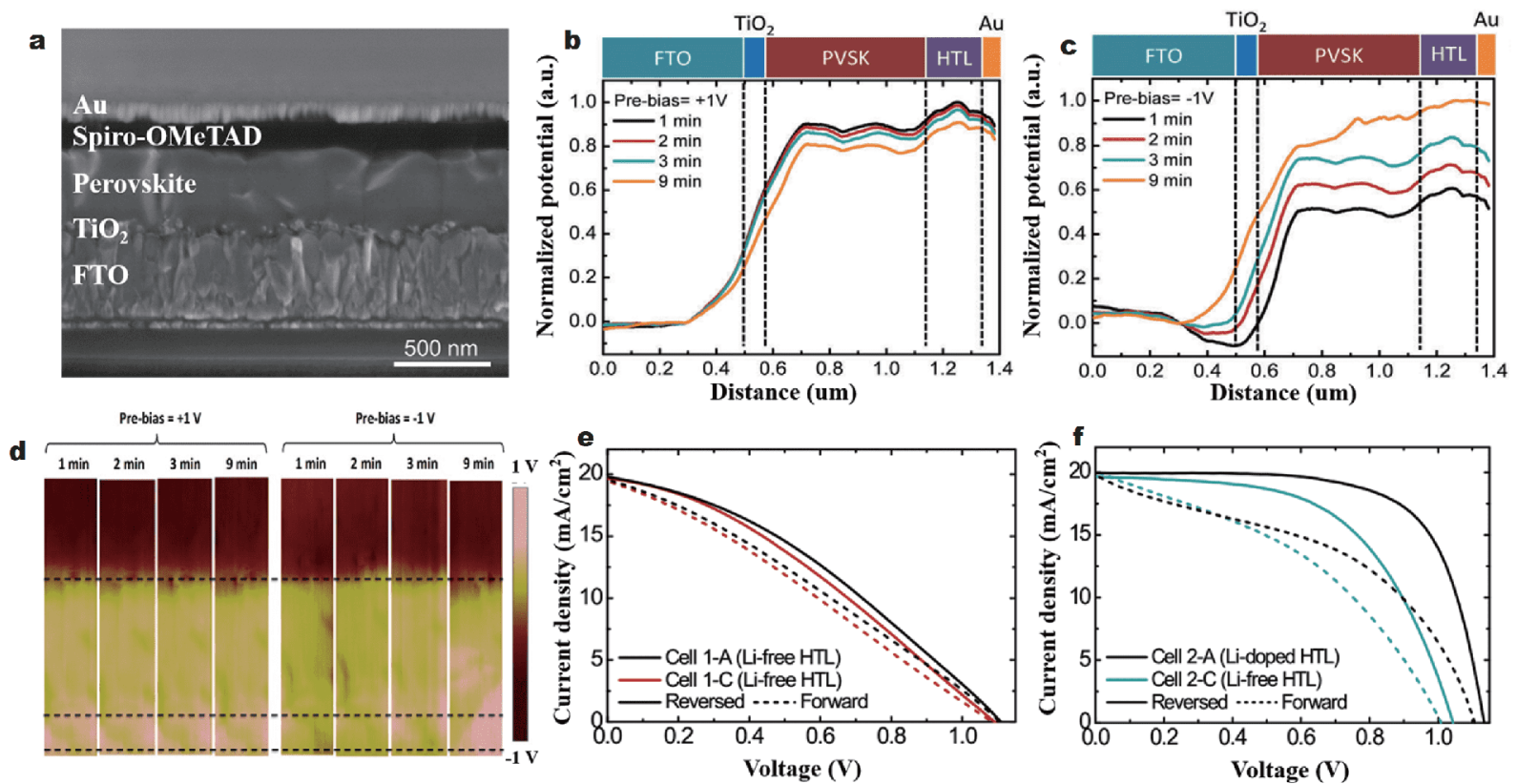

Figure 6 (a) Cross-sectional SEM image of the perovskite solar cell, (b, c) cross-sectional normalized potentials of the perovskite solar cells at positive $(+1 \mathrm{~V})$ and negative $(-1 \mathrm{~V})$ bias, (d) cross-sectional potential images of the perovskite solar cells under $+1 \mathrm{~V}$ pre-bias and $-1 \mathrm{~V}$ pre-bias, (e) $J-V$ curves with Li-free HTL initially and finally, (f) $J-V$ curves without/with Li doped HTL [119]. Copyright 2017, the Royal Society of Chemistry.

understanding of ion migration at the grain boundaries and the surface of hybrid perovskite materials.

\section{CONCLUSIONS AND OUTLOOK}

KPFM, as a non-destructive technique has exceptional functions for detecting local work function at atomic/ molecular scales, offering the accurate surface information such as energy band bending, charge trapping, and surface reconstruction. In this review, the fundamental principle, working modes, instrumental parts and the development of KPFM technique are systematically demonstrated and the applications of KPFM towards the electron beam-sensitive materials are comprehensively reviewed. In particular, this review highlights the promising superiorities of KPFM on exploring the origin and nature of perovskite materials and provides the necessary information for optimizing solar cells, compared with other emerged characterization methods from some certain perspectives. Detailed summaries in terms of KPFM in perovskites range from the energy band structures identification to trap states-induced nonradiative recombination, from phase segregation-induced degradation to ion migration, which are helpful to effectively stimulate the evolution of the perovskite materials as well as the development of perovskite-based solar energy harvesting devices in the future.

Received 10 December 2018; accepted 11 January 2019; published online 14 February 2019

1 Sheldon MT, van de Groep J, Brown AM, et al. Plasmoelectric potentials in metal nanostructures. Science, 2014, 346: 828-831

2 Hoppe H, Glatzel T, Niggemann M, et al. Kelvin probe force microscopy study on conjugated polymer/fullerene bulk heterojunction organic solar cells. Nano Lett, 2005, 5: 269-274

3 Liu L, Li G. Electrical characterization of single-walled carbon nanotubes in organic solar cells by Kelvin probe force microscopy. Appl Phys Lett, 2010, 96: 083302

4 Li M, Liu L, Xiao X, et al. The dynamic interactions between chemotherapy drugs and plasmid DNA investigated by atomic force microscopy. Sci China Mater, 2017, 60: 269-278

5 Kelvin LV. Contact electricity of metals. Phil Mag J Sci, 1898, 46: $82-120$

6 Zisman WA. A new method of measuring contact potential differences in metals. Rev Sci Instruments, 1932, 3: 367-370

7 Nonnenmacher M, O'Boyle MP, Wickramasinghe HK. Kelvin probe force microscopy. Appl Phys Lett, 1991, 58: 2921-2923

8 Jiang CS, Yang M, Zhou Y, et al. Carrier separation and transport in perovskite solar cells studied by nanometre-scale profiling of electrical potential. Nat Commun, 2015, 6: 8397

9 Waegele MM, Chen X, Herlihy DM, et al. How surface potential determines the kinetics of the first hole transfer of photocatalytic water oxidation. J Am Chem Soc, 2014, 136: 10632-10639

10 Wu MC, Chan SH, Lee KM, et al. Enhancing the efficiency of perovskite solar cells using mesoscopic zinc-doped $\mathrm{TiO}_{2}$ as the 
electron extraction layer through band alignment. J Mater Chem A, 2018, 6: 16920-16931

11 Almadori Y, Moerman D, Martinez JL, et al. Multimodal noncontact atomic force microscopy and Kelvin probe force microscopy investigations of organolead tribromide perovskite single crystals. Beilstein J Nanotechnol, 2018, 9: 1695-1704

12 Jang YJ, Kim E, Ahn S, et al. Upconversion-triggered charge separation in polymer semiconductors. J Phys Chem Lett, 2017, 8: 364-369

13 Sun $\mathrm{H}$, Chu H, Wang J, et al. Kelvin probe force microscopy study on nanotriboelectrification. Appl Phys Lett, 2010, 96: 083112

14 Wu H, Si H, Zhang Z, et al. All-inorganic perovskite quantum dot-monolayer $\mathrm{MoS}_{2}$ mixed-dimensional van der Waals heterostructure for ultrasensitive photodetector. Adv Sci, 2018, 5: 1801219

15 Li Y, Ji L, Liu R, et al. A review on morphology engineering for highly efficient and stable hybrid perovskite solar cells. J Mater Chem A, 2018, 6: 12842-12875

16 Yang D, Yang R, Zhang J, et al. High efficiency flexible perovskite solar cells using superior low temperature $\mathrm{TiO}_{2}$. Energy Environ Sci, 2015, 8: 3208-3214

17 Wu WQ, Wang Q, Fang Y, et al. Molecular doping enabled scalable blading of efficient hole-transport-layer-free perovskite solar cells. Nat Commun, 2018, 9: 1625

18 Zhang W, Eperon GE, Snaith HJ. Metal halide perovskites for energy applications. Nat Energy, 2016, 1: 16048

19 Zhao D, Wang C, Song Z, et al. Four-terminal all-perovskite tandem solar cells achieving power conversion efficiencies exceeding 23\%. ACS Energy Lett, 2018, 3: 305-306

20 Polman A, Knight M, Garnett EC, et al. Photovoltaic materials: Present efficiencies and future challenges. Science, 2016, 352: aad 4424

21 Lu J, Lin X, Jiao X, et al. Interfacial benzenethiol modification facilitates charge transfer and improves stability of $\mathrm{cm}$-sized metal halide perovskite solar cells with up to $20 \%$ efficiency. Energy Environ Sci, 2018, 11: 1880-1889

22 Yao D, Zhang C, Pham ND, et al. Hindered formation of photoinactive $\delta$ - $\mathrm{FAPbI}_{3}$ phase and hysteresis-free mixed-cation planar heterojunction perovskite solar cells with enhanced efficiency via potassium incorporation. J Phys Chem Lett, 2018, 9: 21132120

23 Luo D, Yang W, Wang Z, et al. Enhanced photovoltage for inverted planar heterojunction perovskite solar cells. Science, 2018, 360: 1442-1446

24 Fang $\mathrm{R}, \mathrm{Wu} \mathrm{S}$, Chen $\mathrm{W}$, et al. [6,6]-Phenyl- $\mathrm{C}_{61}$-butyric acid methyl ester/cerium oxide bilayer structure as efficient and stable electron transport layer for inverted perovskite solar cells. ACS Nano, 2018, 12: 2403-2414

25 Zuo C, Ding L. Solution-processed $\mathrm{Cu}_{2} \mathrm{O}$ and $\mathrm{CuO}$ as hole transport materials for efficient perovskite solar cells. Small, 2015, 11: 5528-5532

26 Yang M, Zhou Y, Zeng Y, et al. Square-centimeter solutionprocessed planar $\mathrm{CH}_{3} \mathrm{NH}_{3} \mathrm{PbI}_{3}$ perovskite solar cells with efficiency exceeding 15\%. Adv Mater, 2015, 27: 6363-6370

27 Fan R, Zhou N, Zhang L, et al. Toward full solution processed perovskite/Si monolithic tandem solar device with PCE exceeding 20\%. Sol RRL, 2017, 1: 1700149

28 Zhang $\mathrm{H}$, Wang $\mathrm{H}$, Zhu $\mathrm{H}$, et al. Low-temperature solutionprocessed $\mathrm{CuCrO}_{2}$ hole-transporting layer for efficient and pho- tostable perovskite solar cells. Adv Energy Mater, 2018, 8: 1702762

29 Jeong S, Seo S, Shin H. p-Type $\mathrm{CuCrO}_{2}$ particulate films as the hole transporting layer for $\mathrm{CH}_{3} \mathrm{NH}_{3} \mathrm{PbI}_{3}$ perovskite solar cells. RSC Adv, 2018, 8: 27956-27962

30 Wang Z, Gu Y, Qi J, et al. Size dependence and UV irradiation tuning of the surface potential in single conical $\mathrm{ZnO}$ nanowires. RSC Adv, 2015, 5: 42075-42080

31 Yang B, Brown CC, Huang J, et al. Enhancing ion migration in grain boundaries of hybrid organic-inorganic perovskites by chlorine. Adv Funct Mater, 2017, 27: 1700749

32 Bu T, Liu X, Zhou Y, et al. A novel quadruple-cation absorber for universal hysteresis elimination for high efficiency and stable perovskite solar cells. Energy Environ Sci, 2017, 10: 2509-2515

33 Draguta S, Sharia O, Yoon SJ, et al. Rationalizing the light-induced phase separation of mixed halide organic-inorganic perovskites. Nat Commun, 2017, 8: 200

34 Lee JH, Kim J, Kim G, et al. Introducing paired electric dipole layers for efficient and reproducible perovskite solar cells. Energy Environ Sci, 2018, 11: 1742-1751

35 Hoque MNF, He R, Warzywoda J, et al. Effects of moisture-based grain boundary passivation on cell performance and ionic migration in organic-inorganic halide perovskite solar cells. ACS Appl Mater Interfaces, 2018, 10: 30322-30329

36 Ding J, Lian Z, Li Y, et al. The role of surface defects in photoluminescence and decay dynamics of high-quality perovskite $\mathrm{MAPbI}_{3}$ single crystals. J Phys Chem Lett, 2018, 9: 4221-4226

37 Zheng X, Deng Y, Chen B, et al. Dual functions of crystallization control and defect passivation enabled by sulfonic zwitterions for stable and efficient perovskite solar cells. Adv Mater, 2018, 30: 1803428

38 Zheng X, Chen B, Dai J, et al. Defect passivation in hybrid perovskite solar cells using quaternary ammonium halide anions and cations. Nat Energy, 2017, 2: 17102

39 Zhang F, Bi D, Pellet N, et al. Suppressing defects through the synergistic effect of a Lewis base and a Lewis acid for highly efficient and stable perovskite solar cells. Energy Environ Sci, 2018, 11: 3480-3490

40 Tang X, van den Berg M, Gu E, et al. Local observation of phase segregation in mixed-halide perovskite. Nano Lett, 2018, 18: 2172-2178

41 Li C, Tscheuschner S, Paulus F, et al. Iodine migration and its effect on hysteresis in perovskite solar cells. Adv Mater, 2016, 28: 2446-2454

42 Seol D, Jeong A, Han MH, et al. Origin of hysteresis in $\mathrm{CH}_{3} \mathrm{NH}_{3} \mathrm{PbI}_{3}$ perovskite thin films. Adv Funct Mater, 2017, 27: 1701924

43 Peng W, Aranda C, Bakr OM, et al. Quantification of ionic diffusion in lead halide perovskite single crystals. ACS Energy Lett, 2018, 3: 1477-1481

44 Huang J, Yuan Y, Shao Y, et al. Understanding the physical properties of hybrid perovskites for photovoltaic applications. Nat Rev Mater, 2017, 2: 17042

45 Zhu X, Lee J, Lu WD. Iodine vacancy redistribution in organicinorganic halide perovskite films and resistive switching effects. Adv Mater, 2017, 29: 1700527

46 Walsh A, Stranks SD. Taking control of ion transport in halide perovskite solar cells. ACS Energy Lett, 2018, 3: 1983-1990

47 Xiao J, Chang J, Li B, et al. Room temperature ferroelectricity of hybrid organic-inorganic perovskites with mixed iodine and 
bromine. J Mater Chem A, 2018, 6: 9665-9676

48 Long $\mathrm{M}$, Zhang $\mathrm{T}$, Liu M, et al. Abnormal synergetic effect of organic and halide ions on the stability and optoelectronic properties of a mixed perovskite via in situ characterizations. Adv Mater, 2018, 30: 1801562

49 Buin A, Pietsch P, Xu J, et al. Materials processing routes to trapfree halide perovskites. Nano Lett, 2014, 14: 6281-6286

50 Ji F, Pang S, Zhang L, et al. Simultaneous evolution of uniaxially oriented grains and ultralow-density grain-boundary network in $\mathrm{CH}_{3} \mathrm{NH}_{3} \mathrm{PbI}_{3}$ perovskite thin films mediated by precursor phase metastability. ACS Energy Lett, 2017, 2: 2727-2733

51 Saidaminov MI, Kim J, Jain A, et al. Suppression of atomic vacancies via incorporation of isovalent small ions to increase the stability of halide perovskite solar cells in ambient air. Nat Energy, 2018, 3: 648-654

52 Berhe TA, Su WN, Chen $\mathrm{CH}$, et al. Organometal halide perovskite solar cells: degradation and stability. Energy Environ Sci, 2016, 9: 323-356

53 Lee DS, Yun JS, Kim J, et al. Passivation of grain boundaries by phenethylammonium in formamidinium-methylammonium lead halide perovskite solar cells. ACS Energy Lett, 2018, 3: 647-654

54 Yuan Y, Huang J. Ion migration in organometal trihalide perovskite and its impact on photovoltaic efficiency and stability. Acc Chem Res, 2016, 49: 286-293

55 Chen R, Fan F, Dittrich T, et al. Imaging photogenerated charge carriers on surfaces and interfaces of photocatalysts with surface photovoltage microscopy. Chem Soc Rev, 2018, 47: 8238-8262

56 Palermo V, Liscio A, Palma M, et al. Exploring nanoscale electrical and electronic properties of organic and polymeric functional materials by atomic force microscopy based approaches. Chem Commun, 2007, 295: 3326-3337

57 Sadewasser S, Glatzel T. Kelvin Probe Force Microscopy. Berlin: Springer, 2012

58 Giridharagopal R, Cox PA, Ginger DS. Functional scanning probe imaging of nanostructured solar energy materials. Acc Chem Res, 2016, 49: 1769-1776

59 Correa-Baena JP, Abate A, Saliba M, et al. The rapid evolution of highly efficient perovskite solar cells. Energy Environ Sci, 2017, 10: $710-727$

60 Yoo H, Bae C, Yang Y, et al. Spatial charge separation in asymmetric structure of $\mathrm{Au}$ nanoparticle on $\mathrm{TiO}_{2}$ nanotube by lightinduced surface potential imaging. Nano Lett, 2014, 14: 44134417

61 Gratia P, Grancini G, Audinot JN, et al. Intrinsic halide segregation at nanometer scale determines the high efficiency of mixed cation/mixed halide perovskite solar cells. J Am Chem Soc, 2016, 138: 15821-15824

62 Shen $\mathrm{Y}$, Chen X, Yan X, et al. Low-voltage blue light emission from $\mathrm{n}-\mathrm{ZnO} / \mathrm{p}-\mathrm{GaN}$ heterojunction formed by $\mathrm{RF}$ magnetron sputtering method. Curr Appl Phys, 2014, 14: 345-348

63 Hieulle J, Stecker C, Ohmann R, et al. Scanning probe microscopy applied to organic-inorganic halide perovskite materials and solar cells. Small Methods, 2018, 2: 1700295

64 Ben CV, Cho HD, Kang TW, et al. Surface potential measurement of As-doped homojunction $\mathrm{ZnO}$ nanorods by Kelvin probe force microscopy. Surf Interface Anal, 2012, 44: 755-758

65 O'Boyle MP, Hwang TT, Wickramasinghe HK. Atomic force microscopy of work functions on the nanometer scale. Appl Phys Lett, 1999, 74: 2641-2642

66 Lee $\mathrm{H}$, Lee $\mathrm{W}$, Lee $\mathrm{JH}$, et al. Surface potential analysis of na- noscale biomaterials and devices using Kelvin probe force microscopy. J Nanomaterials, 2016, 2016: 1-21

67 Handschuh-Wang S, Wang T, Zhou X. Recent advances in hybrid measurement methods based on atomic force microscopy and surface sensitive measurement techniques. RSC Adv, 2017, 7: 47464-47499

68 Salerno M, Dante S. Scanning Kelvin probe microscopy: challenges and perspectives towards increased application on biomaterials and biological samples. Materials, 2018, 11: 951

69 Palermo V, Palma M, Samorì P. Electronic characterization of organic thin films by Kelvin probe force microscopy. Adv Mater, 2006, 18: 145-164

70 Glatzel T, Sadewasser S, Lux-Steiner MC. Amplitude or frequency modulation-detection in Kelvin probe force microscopy. Appl Surf Sci, 2003, 210: 84-89

71 Melitz W, Shen J, Kummel AC, et al. Kelvin probe force microscopy and its application. Surf Sci Rep, 2011, 66: 1-27

72 Barth C, Foster AS, Henry CR, et al. Recent trends in surface characterization and chemistry with high-resolution scanning force methods. Adv Mater, 2011, 23: 477-501

73 Ranjan R, Prakash A, Singh A, et al. Effect of tantalum doping in a $\mathrm{TiO}_{2}$ compact layer on the performance of planar spiro-OMeTAD free perovskite solar cells. J Mater Chem A, 2018, 6: 10371047

74 Zhang Y, Wang P, Yu X, et al. Enhanced performance and light soaking stability of planar perovskite solar cells using an aminebased fullerene interfacial modifier. J Mater Chem A, 2016, 4: 18509-18515

75 Si H, Kang Z, Liao Q, et al. Design and tailoring of patterned $\mathrm{ZnO}$ nanostructures for energy conversion applications. Sci China Mater, 2017, 60: 793-810

76 Fang Y, Bi C, Wang D, et al. The functions of fullerenes in hybrid perovskite solar cells. ACS Energy Lett, 2017, 2: 782-794

77 Si $\mathrm{H}$, Liao $\mathrm{Q}$, Zhang $\mathrm{Z}$, et al. An innovative design of perovskite solar cells with $\mathrm{Al}_{2} \mathrm{O}_{3}$ inserting at $\mathrm{ZnO}$ /perovskite interface for improving the performance and stability. Nano Energy, 2016, 22: 223-231

78 Tavakoli MM, Giordano F, Zakeeruddin SM, et al. Mesoscopic oxide double layer as electron specific contact for highly efficient and UV stable perovskite photovoltaics. Nano Lett, 2018, 18: 2428-2434

79 Wu H, Kang Z, Zhang Z, et al. Interfacial charge behavior modulation in perovskite quantum dot-monolayer $\mathrm{MoS}_{2} 0 \mathrm{D}-2 \mathrm{D}$ mixed-dimensional van der Waals heterostructures. Adv Funct Mater, 2018, 28: 1802015

80 Yang D, Yang R, Wang K, et al. High efficiency planar-type perovskite solar cells with negligible hysteresis using EDTAcomplexed $\mathrm{SnO}_{2}$. Nat Commun, 2018, 9: 3239

81 Lu K, Lei Y, Qi R, et al. Fermi level alignment by copper doping for efficient ITO/perovskite junction solar cells. J Mater Chem A, 2017, 5: 25211-25219

82 Panigrahi S, Jana S, Calmeiro $\mathrm{T}$, et al. Imaging the anomalous charge distribution inside $\mathrm{CsPbr}_{3}$ perovskite quantum dots sensitized solar cells. ACS Nano, 2017, 11: 10214-10221

83 Cai M, Ishida N, Li X, et al. Control of electrical potential distribution for high-performance perovskite solar cells. Joule, 2018, 2: 296-306

84 Wei W, Zhang Y, Xu Q, et al. Monolithic integration of hybrid perovskite single crystals with heterogenous substrate for highly sensitive X-ray imaging. Nat Photonics, 2017, 11: 315-321 
85 Wang Y, Fullon R, Acerce M, et al. Solution-processed $\mathrm{MoS}_{2}$ / organolead trihalide perovskite photodetectors. Adv Mater, 2017, 29: 1603995

86 Li JJ, Ma JY, Ge QQ, et al. Microscopic investigation of grain boundaries in organolead halide perovskite solar cells. ACS Appl Mater Interfaces, 2015, 7: 28518-28523

87 Fujihira M. Kelvin probe force microscopy of molecular surfaces. Annu Rev Mater Sci, 1999, 29: 353-380

88 Shao Y, Xiao Z, Bi C, et al. Origin and elimination of photocurrent hysteresis by fullerene passivation in $\mathrm{CH}_{3} \mathrm{NH}_{3} \mathrm{PbI}_{3}$ planar heterojunction solar cells. Nat Commun, 2014, 5: 5784

89 Adhikari N, Dubey A, Khatiwada D, et al. Interfacial study to suppress charge carrier recombination for high efficiency perovskite solar cells. ACS Appl Mater Interfaces, 2015, 7: 2644526454

90 Kronik L, Shapira Y. Surface photovoltage spectroscopy of semiconductor structures: at the crossroads of physics, chemistry and electrical engineering. Surf Interface Anal, 2001, 31: 954-965

91 Liqiang J, Xiaojun S, Jing S, et al. Review of surface photovoltage spectra of nano-sized semiconductor and its applications in heterogeneous photocatalysis. Sol Energy Mater Sol Cells, 2003, 79: 133-151

92 Zhao S, Xie J, Cheng G, et al. General nondestructive passivation by 4-fluoroaniline for perovskite solar cells with improved performance and stability. Small, 2018, 14: 1803350

93 Zhang W, Pathak S, Sakai N, et al. Enhanced optoelectronic quality of perovskite thin films with hypophosphorous acid for planar heterojunction solar cells. Nat Commun, 2015, 6: 10030

$94 \mathrm{Si} \mathrm{H}$, Liao Q, Kang Z, et al. Deciphering the $\mathrm{NH}_{4} \mathrm{PbI}_{3}$ intermediate phase for simultaneous improvement on nucleation and crystal growth of perovskite. Adv Funct Mater, 2017, 27: 1701804

95 Li M, Yan X, Kang Z, et al. Enhanced efficiency and stability of perovskite solar cells via anti-solvent treatment in two-step deposition method. ACS Appl Mater Interfaces, 2017, 9: 7224-7231

96 Kim HD, Ohkita H, Benten H, et al. Photovoltaic performance of perovskite solar cells with different grain sizes. Adv Mater, 2016, 28: 917-922

97 Yun JS, Kim J, Young T, et al. Humidity-induced degradation via grain boundaries of $\mathrm{HC}\left(\mathrm{NH}_{2}\right)_{2} \mathrm{PbI}_{3}$ planar perovskite solar cells. Adv Funct Mater, 2018, 28: 1705363

98 Yun JS, Ho-Baillie A, Huang S, et al. Benefit of grain boundaries in organic-inorganic halide planar perovskite solar cells. J Phys Chem Lett, 2015, 6: 875-880

99 Zhang XM, Lu MY, Zhang Y, et al. Fabrication of a highbrightness blue-light-emitting diode using a $\mathrm{ZnO}$-nanowire array grown on p-GaN thin film. Adv Mater, 2009, 21: 2767-2770

100 Faraji N, Qin C, Matsushima T, et al. Grain boundary engineering of halide perovskite $\mathrm{CH}_{3} \mathrm{NH}_{3} \mathrm{PbI}_{3}$ solar cells with photochemically active additives. J Phys Chem C, 2018, 122: 4817-4821

101 Zhou Y, Game OS, Pang S, et al. Microstructures of organometal trihalide perovskites for solar cells: their evolution from solutions and characterization. J Phys Chem Lett, 2015, 6: 4827-4839

102 Cho Y, Soufiani AM, Yun JS, et al. Mixed 3D-2D passivation treatment for mixed-cation lead mixed-halide perovskite solar cells for higher efficiency and better stability. Adv Energy Mater, 2018, 8: 1703392

103 Li W, Rothmann MU, Liu A, et al. Phase segregation enhanced ion movement in efficient inorganic $\mathrm{CsPbIBr}_{2}$ solar cells. Adv Energy Mater, 2017, 7: 1700946

104 Son DY, Lee JW, Choi YJ, et al. Self-formed grain boundary healing layer for highly efficient $\mathrm{CH}_{3} \mathrm{NH}_{3} \mathrm{PbI}_{3}$ perovskite solar cells. Nat Energy, 2016, 1: 16081

105 Dymshits A, Henning A, Segev G, et al. The electronic structure of metal oxide/organo metal halide perovskite junctions in perovskite based solar cells. Sci Rep, 2015, 5: 8704

106 Jung HR, Nguyen BP, Jin HJ, et al. Surface potential mapping and n-type conductivity in organic-inorganic lead iodide crystals. CrystEngComm, 2018, 20: 6551-6556

107 Jung HR, Kim GY, Nguyen BP, et al. Optical and scanning probe identification of electronic structure and phases in $\mathrm{CH}_{3} \mathrm{NH}_{3} \mathrm{PbBr}_{3}$ crystal. J Phys Chem C, 2017, 121: 21930-21934

108 Chen S, Wen X, Yun JS, et al. Spatial distribution of lead iodide and local passivation on organo-lead halide perovskite. ACS Appl Mater Interfaces, 2017, 9: 6072-6078

109 Li Z, Li J, Ding D, et al. Direct observation of perovskite photodetector performance enhancement by atomically thin interface engineering. ACS Appl Mater Interfaces, 2018, 10: 36493-36504

110 Meloni S, Moehl T, Tress W, et al. Ionic polarization-induced current-voltage hysteresis in $\mathrm{CH}_{3} \mathrm{NH}_{3} \mathrm{PbX}_{3}$ perovskite solar cells. Nat Commun, 2016, 7: 10334

111 Liu Y, Renna LA, Thompson HB, et al. Role of ionic functional groups on ion transport at perovskite interfaces. Adv Energy Mater, 2017, 7: 1701235

112 Collins L, Ahmadi M, Wu T, et al. Breaking the time barrier in Kelvin probe force microscopy: fast free force reconstruction using the G-mode platform. ACS Nano, 2017, 11: 8717-8729

113 Kim YC, Jeon NJ, Noh JH, et al. Beneficial effects of $\mathrm{PbI}_{2}$ incorporated in organo-lead halide perovskite solar cells. Adv Energy Mater, 2016, 6: 1502104

114 Xiao JW, Shi C, Zhou C, et al. Contact engineering: electrode materials for highly efficient and stable perovskite solar cells. Sol RRL, 2017, 1: 1700082

115 Zhang T, Long M, Yan K, et al. Crystallinity preservation and ion migration suppression through dual ion exchange strategy for stable mixed perovskite solar cells. Adv Energy Mater, 2017, 7: 1700118

116 Shao Y, Fang Y, Li T, et al. Grain boundary dominated ion migration in polycrystalline organic-inorganic halide perovskite films. Energy Environ Sci, 2016, 9: 1752-1759

117 Hermes IM, Hou Y, Bergmann VW, et al. The interplay of contact layers: how the electron transport layer influences interfacial recombination and hole extraction in perovskite solar cells. J Phys Chem Lett, 2018, 9: 6249-6256

118 Wu F, Zhang M, Lu H, et al. Triple stimuli-responsive magnetic hollow porous carbon-based nanodrug delivery system for magnetic resonance imaging-guided synergistic photothermal/chemotherapy of cancer. ACS Appl Mater Interfaces, 2018, 10: 21939-21949

119 Yun JS, Seidel J, Kim J, et al. Critical role of grain boundaries for ion migration in formamidinium and methylammonium lead halide perovskite solar cells. Adv Energy Mater, 2016, 6: 1600330

120 Yuan Y, Li T, Wang Q, et al. Anomalous photovoltaic effect in organic-inorganic hybrid perovskite solar cells. Sci Adv, 2017, 3: e1602164

121 Yuan Y, Chae J, Shao Y, et al. Photovoltaic switching mechanism in lateral structure hybrid perovskite solar cells. Adv Energy Mater, 2015, 5: 1500615

122 Ahmadi M, Collins L, Puretzky A, et al. Exploring anomalous polarization dynamics in organometallic halide perovskites. Adv Mater, 2018, 30: 1705298 
123 Wu T, Collins L, Zhang J, et al. Photoinduced bulk polarization and its effects on photovoltaic actions in perovskite solar cells. ACS Nano, 2017, 11: 11542-11549

124 Gottesman R, Lopez-Varo P, Gouda L, et al. Dynamic phenomena at perovskite/electron-selective contact interface as interpreted from photovoltage decays. Chem, 2016, 1: 776-789

125 Zhang J, Chen R, Wu Y, et al. Extrinsic movable ions in $\mathrm{MAPbI}_{3}$ modulate energy band alignment in perovskite solar cells. Adv Energy Mater, 2017, 8: 1701981

126 Weber SAL, Hermes IM, Turren-Cruz SH, et al. How the formation of interfacial charge causes hysteresis in perovskite solar cells. Energy Environ Sci, 2018, 11: 2404-2413

127 Li Z, Xiao C, Yang Y, et al. Extrinsic ion migration in perovskite solar cells. Energy Environ Sci, 2017, 10: 1234-1242

Acknowledgements This work was supported by the National Key Research and Development Program of China (2016YFA0202701), the
Overseas Expertise Introduction Projects for Discipline Innovation (111 project, B14003), the National Natural Science Foundation of China (51527802, 51232001, 51702014 and 51372020), the National Major Research Program of China (2013CB932602), Beijing Municipal Science \& Technology Commission (Z161100002116027), the State Key Laboratory for Advanced Metals and Materials, and the Fundamental Research Funds for the Central Universities (FRF-TP-18-042A1).

Author contributions Kang $\mathrm{Z}$ and $\mathrm{Si} \mathrm{H}$ contributed equally to this work. Kang $\mathrm{Z}$ and Si H wrote the manuscript. Zhang Y, Liao Q and Zhang $\mathrm{Z}$ investigated and analyzed published literatures. Shi $\mathrm{M}$ and $\mathrm{Xu}$ $\mathrm{C}$ summarized the application of KPFM on trap states investigation. Fan W, Ma S and Kausar A analyzed the fundamental principle and development status of KPFM. All authors discussed and provided feedback on the manuscripts structure, arguments and conclusions.

Conflict of interest The authors declare no conflict of interest.

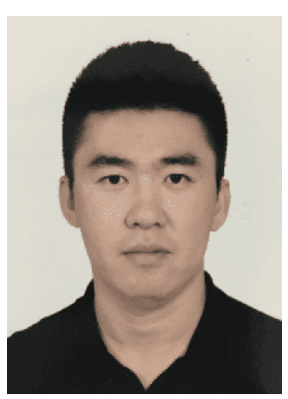

Zhuo Kang received his $\mathrm{BS}$ and $\mathrm{PhD}$ degrees in Materials Science and Engineering from University of Science and Technology Beijing in the year 2011 and 2016, respectively. His research interest includes controllable synthesis and characterization of nanomaterials, as well as their applications in photoelectrochemical and electrochemical systems, perovskite solar cell, and biosensing devices. He has published more than 40 papers in peer-reviewed scientific journals.

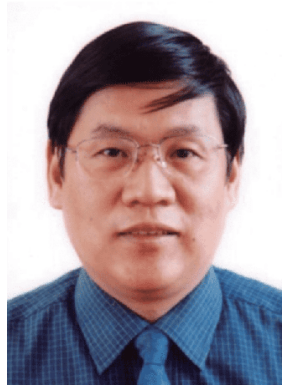

Yue Zhang is a professor of material physics and vice-president of the University of Science and Technology Beijing, China. He has been awarded the financial support for Outstanding Young Scientist Foundation of China and selected as the chief scientist of Major National Scientific Research Projects. His research focuses on functional nano-materials and nano-devices, new energy materials, and nanoscale failure and service behavior. He has published more than 400 papers in peer-reviewed scientific journals and 8 monograph, and held 30 patents. His publication has been cited more than 10,000 times.

\section{开尔文探针力显微镜在钻钛矿太阳能电池中的应用}

康卓 $^{1 \dagger}$, 司浩楠 ${ }^{1{ }^{*}}$, 时明月 ${ }^{1}$, 徐晨哲 ${ }^{1}$, 范文强 ${ }^{1}$, 马双飞 ${ }^{1}$, Ammarah Kausar ${ }^{1}$, 廖庆亮 ${ }^{1}, 弓^{2}$ 铮 $^{1}$, 张跃 $^{1,2^{*}}$

摘要 开尔文探针力显微镜在获得样品表面形貌的基础上可同时得到表面功函数, 且具有纳米级高分辨率, 是原位探究样品表面信息的 有效表征手段. 目前, 开尔文探针力显微镜作为一种无损检测手段, 在探测对水、氧和电子束辐射极其敏感的钲钛矿材料方面显示出独特 的优势与潜力. 本论文系统地介绍了开尔文探针力显微镜的基本原理和工作模式, 并深入地阐述了其在研究钙钛矿太阳能电池能带结 构、载流子传输动力学、缺陷态、晶相种类和离子迁移方面的应用前景. 开尔文探针力显微镜为揭示钙钛矿材料和太阳能电池的独特性 能提供了新颖有效的方法. 